\title{
"Rio da Vida Coletivo": empoderamento, emancipação e práxis
}

\author{
Raquel de Oliveira Barreto \\ Centro Universitário de Belo Horizonte \\ Ana Paula Paes de Paula \\ Universidade de Minas Gerais
}

\begin{abstract}
Na perspectiva neoliberal e neoconservadora de empoderamento, há uma noção generalizada de que a pobreza desempodera e que a saída da situação de risco social por meio de recursos materiais é o caminho para o empoderamento. O objetivo deste artigo é questionar essa noção, resgatando a centralidade dos recursos simbólicos para evidenciar que o empoderamento é possível mesmo em condições de pobreza, se considerado em uma perspectiva emancipatória. Para isso, realiza-se uma revisão teórica que problematiza a pobreza e a exclusão quanto aos recursos simbólicos, discute o conceito de empoderamento e aborda suas relações com a práxis. Em seguida, são analisadas as evidências empíricas do caso "Vale de cidadania" e apresentadas as considerações finais.
\end{abstract}

Palavras-chave: pobreza; exclusão social; empoderamento; projeto social.

"Río de la vida colectivo": empoderamiento, emancipación y praxis

Bajo la perspectiva neoliberal y neoconservadora de empoderamiento, hay una noción generalizada de que la pobreza priva de poder y que la salida de la situación de riesgo social a través de recursos materiales es el camino para el empoderamiento. Este artículo objetiva cuestionar esa noción, rescatando la centralidad de los recursos simbólicos para evidenciar que el empoderamiento es posible incluso en condiciones de pobreza, cuando considerado desde una perspectiva emancipadora. Para ello, se realiza una revisión teórica que problematiza la pobreza y la exclusión con relación a los recursos simbólicos, discute el concepto de empoderamiento y aborda sus relaciones con la praxis. A continuación, se analizan las evidencias empíricas del caso "Valle de ciudadanía" y se presentan las consideraciones finales.

Palabras Clave: pobreza; exclusión social; empoderamiento; proyecto social.

"Collective life river": empowerment, emancipation, and praxis

From the neoliberal and neoconservative empowerment perspective, there is a widespread notion that poverty disempowers and that leaving social risk through material resources is the path towards

Artigo recebido em 10 mar. 2013 e aceito em 14 nov. 2013.

Rev. Adm. Pública - Rio de Janeiro 48(1):111-30, jan./fev. 2014 
empowerment. This article aims to put this notion into question, resuming the centrality of symbolic resources to make clear that empowerment is possible even under poverty conditions, when viewed from an emancipatory perspective. For this, we conduct a theoretical review that debates poverty and exclusion with regard to the symbolic resources, discusses the concept of empowerment, and addresses its relations to praxis. Then, we analyze the empirical evidence from the case "Citizenship valley" and present the final remarks.

KEYWORDs: poverty; social exclusion; empowerment; social project.

\section{Introdução}

Atualmente, as ações governamentais na área social têm se pautado inicialmente na transferência de renda, visando a atender as necessidades basilares das pessoas para então dar o próximo passo, como é o caso do Programa Bolsa Família do atual governo federal (Sant'ana, 2007). No entanto, a literatura sobre o fenômeno da pobreza e da exclusão aponta que esta condição não envolve somente a carência material básica, mas uma multiplicidade de dimensões subjetivas. Nesse sentido, ressalta-se a importância de as ações governamentais superarem a provisão material, abarcando também as dimensões subjetivas complementares (Bronzo, 2006).

Diante da dificuldade governamental de amenizar tal situação, o papel dos projetos sociais revela-se fundamental. Na maioria dos casos, esses projetos têm surgido por iniciativa da sociedade civil com o intuito de olhar pelas pessoas em situação de vulnerabilidade, seja por motivações financeiras, ou por outras causas diversas. E nesta tentativa de buscar caminhos para a alteração desta realidade marcada pelas desigualdades, algumas novas categorias teóricas surgiram. É o caso do empoderamento, conceito polissêmico e complexo que objetivamos tratar neste artigo.

O empoderamento é considerado uma das formas de se combater o quadro de pobreza e exclusão social, sendo um fenômeno em voga tanto nos estudos acadêmicos quanto nas atuações das agências de desenvolvimento e de projetos sociais. Grosso modo, uma das conceituações de empoderamento refere-se ao fenômeno em que as pessoas passam a ter controle sobre os recursos, sejam eles físicos ou simbólicos. No entanto, diante de uma perspectiva neoliberal/ neoconservadora, os recursos físicos acabam ganhando mais centralidade, pois há uma noção generalizada de que, se a pobreza desempodera, a saída da situação de risco social pela via material é o caminho para o empoderamento. O objetivo deste artigo é questionar essa noção, resgatando a centralidade dos recursos simbólicos para evidenciar que o empoderamento é possível mesmo em condições de pobreza, se considerado em uma perspectiva emancipatória. A solução do problema material da pobreza não evita a condição de exclusão, mas o sujeito na situação de pobreza que efetivamente se empodera deixa de se posicionar como um excluído. A fim de fazer estas reflexões, realizamos um percurso teórico sobre o conceito para em seguida buscar evidências empíricas desta proposição na investigação do projeto "Vale de Cidadania", empreendido pelo "Programa Polos Reprodutores de Cidadania" da Universidade Federal de Minas Gerais (UFMG). 
Tendo em vista tal objetivo, este trabalho está estruturado em cinco seções, incluindo esta introdução. Em seguida, é apresentada a revisão teórica que problematiza a questão da pobreza e da exclusão no que se refere aos recursos simbólicos, discute o conceito de empoderamento e aborda suas relações com a práxis. Na sequência apresentam-se o caso, as considerações finais do trabalho e as recomendações para futuras pesquisas.

\section{Fundamentação teórica}

\subsection{Pobreza e exclusão: indo além da privação material}

De modo geral, a pobreza costuma ser limitada à questão da falta de acesso a bens materiais, ou seja, à falta de dinheiro. No entanto, como explicita Bronzo (2006), a pobreza deve ser entendida de forma mais ampla, isto é, ela envolve, além da carência no atendimento das necessidades básicas, questões relacionais e de natureza psicossocial. São essas outras dimensões que conferem complexidade ao tema. A autora ressalta que a exposição contínua a essas carências múltiplas caracteriza o estado de pobreza crônica. Baseando-se nesta perspectiva, concebe-se a pobreza como "multidimensional e multifacetada".

O mesmo entendimento existe com relação à exclusão social. Segundo Gomà (2004), a sociedade está vivenciando uma modernidade reflexiva, em que coexistem novas e múltiplas desigualdades. Isso porque as diversas transformações socioeconômicas e culturais modificaram os padrões até então vigentes, gerando redefinições do espaço público e do papel do governo. O autor explicita que é neste contexto que se insere o conceito de exclusão, o qual seria, para ele, mais amplo do que o da pobreza. A partir do modelo analítico apresentado a seguir, Gomà (2004) define a exclusão social como a congruência entre desigualdades materiais intensas e graves fraturas no tecido social.

Quadro 1

As diversas faces das carências sociais

\begin{tabular}{|c|c|c|c|}
\hline \multicolumn{2}{|c|}{} & \multicolumn{2}{|c|}{ Desigualdades na distribuição de recursos materiais } \\
\cline { 2 - 4 } & Elevadas & Baixas \\
\hline $\begin{array}{c}\text { Fraturas nos vínculos } \\
\text { de integração } \\
\text { comunitária }\end{array}$ & Fortes & EXCLUSÃO & SEGMENTAÇÃO \\
\cline { 2 - 4 } & Fracos & POBREZA & COESÃO \\
\hline
\end{tabular}

Fonte: Baseado em Gomà (2004).

Para o autor, a pobreza ocorre em função do desprovimento de bens materiais, mas não há necessariamente intensas rupturas no tecido social, o que ameniza um pouco tal situação de precariedade. Isso é perceptível quando se analisam os conglomerados urbanos, em que as pessoas passam por grandes necessidades, mas que têm um senso comunitário, que faz com 
que os moradores se ajudem e se articulem, mesmo que de forma bastante incipiente, para reivindicarem seus direitos.

Já a exclusão envolve, além da grande desigualdade, problemas no que tange à falta de vínculos, de relações de cooperação e autoajuda e, neste sentido, a quebra desses laços significaria a passagem da pobreza para a exclusão. A compreensão destes conceitos por parte dos agentes (governo, mercado e sociedade civil) se faz importante para o delineamento de ações mais efetivas, que não se pautem somente na provisão de bens materiais, mas que, paralelamente, abordem as dimensões subjetivas, ou seja, os valores, o autodesenvolvimento, a participação, dentre outras (Bronzo, 2006).

Nos últimos anos, o empoderamento se tornou a palavra de ordem das agências de desenvolvimento e demais atores sociais no que se refere à redução da pobreza e da exclusão social. Na próxima seção pretendemos discutir como a noção de que a pobreza desempodera tem levado ao falso entendimento de que o provimento de recursos materiais empodera. $\mathrm{O}$ objetivo é resgatar a centralidade dos recursos simbólicos no que se refere ao conceito de empoderamento, demonstrando que ele implica mais retirar as pessoas da situação de risco social pela via material, pois depende de um novo posicionamento do sujeito perante sua condição de pobreza, do que poder evitar que ele se torne um excluído.

\subsection{Empoderamento: resgatando a centralidade dos recursos simbólicos no conceito}

A literatura sobre empoderamento (Perkins, 1995; Rappaport, 1995; Romano, 2002; Antunes, 2002; Gohn, 2004; Horochovski, 2006; Horochovski e Meirelles, 2007) evidencia a polissemia do conceito, que vem sendo discutida por alguns autores. Nesta direção, Horochovski e Meirelles (2007) apontam duas perspectivas: a perspectiva neoconservadora/neoliberal e a perspectiva gramsciana, freireana e habermasiana. Para os autores, a primeira perspectiva vê o empoderamento como fortalecimento da esfera privada, em alinhamento com a visão neoliberal/neoconservadora, que delega para a sociedade civil a resolução de seus problemas. A segunda perspectiva trata o empoderamento como reforço de um espaço público de transformação e emancipação dos grupos dominados e excluídos.

Romano (2002) faz uma descrição clara da primeira perspectiva, indicando que esta não considera devidamente as assimetrias de poder presentes na sociedade, que reforçam a pobreza e a exclusão, pois focaliza principalmente a assistência social ao invés dos direitos sociais e valoriza mais a eficiência econômica dos projetos do que as dimensões afetivas, psicológicas, culturais e políticas do empoderamento. De acordo com Horochovski e Meirelles (2007), os autores alinhados com a segunda perspectiva defendem que é preciso levar em consideração as assimetrias de recursos materiais e simbólicos nas esferas pública e privada, ou seja, é preciso equilibrar as relações de poder de modo que os que têm menos recursos sejam contemplados, o que demonstra, na visão deles, uma identidade entre empoderamento e equidade. Identificado com a segunda perspectiva, Amartya Sen (2001) afirma que o empo- 
deramento significa a ampliação das possibilidades de controle, pelo sujeito ou grupos organizados, dos aspectos fundamentais relacionados à sua própria existência. A trajetória desse conceito está intimamente relacionada com a emergência dos sujeitos coletivos nos anos 1960 e o uso da palavra empowerment pelos movimentos feministas e negros (Perkins, 1995; Antunes, 2002), que foram analisados pelos pesquisadores nas perspectivas de Gramsci, Freire e Habermas. Assim, a ideia de empoderamento vem da própria tradução do termo em inglês, que significa atribuir poder, o que de fato resgata a noção de equidade.

No entanto, o que pretendemos enfatizar é que a equidade simbólica deveria ter mais peso do que a equidade material, pois frequentemente se defende que a pobreza desempodera, o que pode sugerir uma falsa noção de que o simples provimento de recursos materiais é o caminho para o empoderamento, especialmente se consideramos a perspectiva neoliberal/ neoconservadora. O problema é que, quando se enfatiza a solução material da pobreza sem levar em consideração os recursos simbólicos, a tendência é que a situação de exclusão social permaneça. A definição de empoderamento da perspectiva denominada gramsciana, freireana e habermasiana coloca o foco nos recursos, tanto materiais quanto simbólicos, mas acreditamos que a maior ênfase deveria ser dada à autonomia e à práxis que estão relacionadas ao conceito de empoderamento. Assim, buscamos evidenciar que o empoderamento é possível mesmo em condições de pobreza e que deixar a situação de risco social do ponto de vista material não significa necessariamente empoderar-se, pois isto não é suficiente para superar a situação de exclusão. Além disso, tentamos ampliar o conceito de empoderamento da perspectiva gramsciana, freireana e habermasiana de modo a ficar mais alinhado com os conceitos defendidos por estes autores, em especial Freire. Para isto, a partir da literatura, discutiremos na subseção seguinte as relações entre empoderamento e práxis, para depois analisá-la do ponto de vista empírico, de modo a consolidar o que denominamos perspectiva emancipatória do empoderamento.

Partindo de Romano (2002), sustentamos que a concepção de poder que melhor fundamenta o conceito de empoderamento deve ressaltar a visão foucaultiana crítica (não estruturalista), na qual o poder se revela como uma forma de resistência. E, nesse sentido, retoma-se a ideia de um poder que não se baseia na dominação por si só, mas um poder de transformação da realidade que se relaciona ao conceito de emancipação humana. A temática da pobreza e da exclusão envolve as relações de dominação da sociedade, de modo que se torna plausível pensar que a superação desse problema perpasse a alteração das estruturas de poder.

Outro aspecto interessante abordado por Romano (2002) diz respeito à ideia do empoderamento como algo que pode ser imposto ou atribuído às pessoas. Partindo-se dessa perspectiva, empoderar seria possível mais por meio da acessibilidade a bens ou serviços do que pelo incentivo à participação real das pessoas e seu autodesenvolvimento. Críticas também são apontadas em relação à ideia de que o empoderamento consiste em uma técnica ou conteúdo sistematizado, passível de ser transmitido via cursos ou treinamentos, o que também é uma visão equivocada do conceito.

De acordo com Martins e colaboradores (2009), o fenômeno que circunda o empoderamento equivale ao conceito de libertação de Paulo Freire, de modo que recomendam o uso da 
terminologia empoderamento/libertação. Concordamos com essa interpretação, pois Paulo Freire nos permite uma definição mais ampla de empoderamento, embora o autor não tenha tratado especificamente de tal conceito. Foi no contexto da educação e da filosofia que o autor pensou sobre o conceito em um sentido transformador (Valoura, 2012). Para o autor, este estaria relacionado a um processo de evolução humana, o qual seria alcançado pelas pessoas por meio de suas próprias ações. As considerações de Romano (2002) vão de encontro às ideias de Freire, pois defendem a superação das condições de dominação e das privações das liberdades substantivas. O empoderamento envolve uma mudança nas relações de poder existentes, de forma a proporcionar às pessoas vislumbrar alternativas para a sua condição atual e, mais importante ainda, entender o porquê de a realidade configurar-se da forma como se apresenta. É essa tomada de consciência, defendida por Freire e Romano, e esse acesso à liberdade substantiva que revelam a potencialidade envolvida no processo de empoderamento.

Na seção seguinte, pretendemos evidenciar que o conceito de empoderamento se entrelaça com o conceito de práxis, de modo que resgatamos o mesmo em Castoriadis e Freire para evidenciar as relações entre os pensamentos desses autores com o objetivo de consolidar uma perspectiva emancipatória para o empoderamento.

\subsection{Práxis, autonomia e coletividade: as contribuições de alguns autores para a discussão do empoderamento}

No livro A instituição imaginária da sociedade (1982), o autor Cornelius Castoriadis aborda a temática da transformação da sociedade envolvendo questões como a práxis e a autonomia. A relação estabelecida aqui com o conceito de empoderamento é que a sua essência perpassa a ideia de autonomia proposta pelo autor, uma autonomia que é o meio e o fim da práxis revolucionária, ou seja, da ação (do fazer) de mudança da realidade que visa proporcionar a autonomia de todos. O processo de empoderamento corresponderia a essa busca pela autonomia, individual e coletiva, sendo esse um processo que, inevitavelmente, implica a transformação da realidade.

Ao tratar do desejo de mudança por meio do projeto revolucionário, Castoriadis (1982) elucida um conceito importante: o da práxis. "Chamamos de práxis este fazer no qual o outro ou os outros são visados como seres autônomos e considerados como o agente essencial do desenvolvimento de sua própria autonomia" (Castoriadis, 1982:4). Destacam-se nesta definição dois pontos essenciais: a autonomia como fundamento e objetivo do fazer e seu caráter coletivo. Este último é extremamente importante, na medida em que expõe a questão-chave para a práxis: o outro. O autor argumenta que o elemento da práxis é o real e, portanto, sendo este ilimitado, instável e irredutível a uma ordem pré-constituída, ela não se baseia em uma verdade absoluta. Outro aspecto importante é a consideração de que nesta atividade de fazer, o indivíduo atua, modifica, mas também é modificado. O projeto revolucionário seria, portanto, um elemento da práxis, o qual tem como objetivo transformar a sociedade atual em uma sociedade voltada para a autonomia de todos, transformação esta somente realizável por meio da ação autônoma. 
Ao descrever as "raízes subjetivas do projeto revolucionário", o autor revela indícios do que seria na sua visão a concretização da autonomia: um trabalho que tenha sentido pra o indivíduo, decisões coletivas acerca do mesmo, poder sobre as decisões sociais, ter acesso a informação, dentre outros. E é neste sentido, do indivíduo tornar-se sujeito da sua própria história, que o empoderamento está sendo tratado neste artigo. No que tange à autonomia, o autor expõe que esta pode ser analisada sob o ponto de vista individual e coletivo. No nível individual, a autonomia seria a concretização da máxima freudiana "Onde era o Id será o Ego". De forma simplificada, pode-se dizer que o Id corresponde ao local de origem das pulsões, o inconsciente, e o Ego seria a consciência. Tal máxima indica, portanto, a conquista do Id pelo Ego. No entanto, essa conquista não seria a repressão ou eliminação das pulsões, o que seria impossível, mas a tomada de lugar da consciência como instância de decisão. Ou seja, na verdade, a autonomia seria o estabelecimento de outra relação entre o consciente e o inconsciente.

Tal argumento se justifica pela ideia de que a regulação pelo inconsciente é a submissão a uma lei de outro, que não eu. Citando Lacan, Castoriadis explicita que "O inconsciente é o discurso do outro", ou seja, o inconsciente seria um discurso estranho que está em mim, não o discurso de um outro eu desconhecido, mas de "de um outro em mim" (Castoriadis, 1982:124). Tal discussão torna-se importante na medida em que o discurso do outro se relaciona com o imaginário, isto é, esse discurso faz com que o sujeito perceba o mundo e a si mesmo de forma distorcida. Esse imaginário então autonomiza-se, alcançando um alto grau de "realismo", criando para o sujeito sua realidade e seus desejos. Assim, torna-se claro o argumento: "Um sujeito autônomo é aquele que sabe ter boas razões para concluir: isso é bem verdadeiro, e: isso é bem meu desejo" (Castoriadis, 1982:126).

No entanto, apesar de o entendimento da autonomia no nível individual ser extremamente importante, não se pode perder de vista o caráter coletivo da práxis, isto é, a ideia de que esta tem como elemento-chave a existência e a relação com o outro. Nas palavras do autor: "A concepção que apresentamos mostra ao mesmo tempo que não podemos desejar a autonomia sem desejá-la para todos e que sua realização só pode conceber-se plenamente como empreitada coletiva" (Castoriadis, 1982:129, grifos nossos).

Assim como Castoriadis, Freire também partilha a ideia de que a discussão do fenômeno perpassa a coletividade, pois para o educador a práxis é, antes de tudo, um ato social (Valoura, 2012; Pase, 2007). Para Freire (1985:33), esta tarefa de transformação da realidade pertence ao grupo dos oprimidos: "Está aí a grande tarefa humanista e histórica dos oprimidos - libertar a si e aos opressores". Neste sentido, caberia aos oprimidos a busca pela libertação de todos, a qual, segundo o autor, pode ser alcançada por meio da práxis. "Quem, mais que eles, para ir compreendendo a necessidade da libertação? Libertação a que não chegarão por acaso, mas pela práxis de sua busca, pelo conhecimento e reconhecimento da necessidade de lutar por ela" (Freire, 1985:34).

Um aspecto importante refere-se ao fato de que a relação oprimido-opressor é a que predomina na mente dos indivíduos, ou melhor, eles são "formados" compreendendo tal relação como verdadeira, como certa. Neste sentido, tem-se o risco de que, na luta contra a relação de 
opressão, o indivíduo se torne opressor. É interessante destacar que esta passagem de oprimido a opressor pode se dar, muitas vezes, em função daquilo que o autor denomina de medo da liberdade. Para os opressores, o medo se dá pela perda da liberdade de oprimir (perda do poder), já para os oprimidos, este seria o medo de assumi-la. Isso porque esse medo, segundo Freire (1985:37), provém do temor da responsabilidade resultante da libertação, nas suas palavras:

Os oprimidos, que introjetam a "sombra" dos opressores e seguem suas pautas, temem a liberdade, na medida em que esta, implicando a expulsão desta sombra, exigiria deles que "preenchessem" o "vazio" deixado pela expulsão com outro "conteúdo" — o de sua autonomia. O de sua responsabilidade, sem o que não seriam livres. (grifos nossos)

Neste contexto, o autor, da mesma forma que Castoriadis, utiliza-se do conceito de autonomia como um elemento essencial da práxis libertadora, desse fazer capaz de transformar a realidade. No entanto, se limitados por este medo da liberdade, os indivíduos podem, como explicitado anteriormente, simplesmente permanecer na realidade em que estão. Decidir entre lutar ou não se revela, portanto, o dilema do oprimido. Neste sentido, os indivíduos se encontram nesta dualidade em que

Querem ser, mas temem ser. São eles e ao mesmo tempo são o outro introjetado neles, como consciência opressora. Sua luta se trava entre serem eles mesmos ou serem duplos. (...) Entre serem espectadores ou atores. Entre atuarem ou terem a ilusão de que atuam na atuação do opressor. (Freire, 1985:38; grifos nossos)

Essa dualidade remete à proposição de Castoriadis da autonomia como a alteração da relação entre consciente e inconsciente. Isso porque, como explicitado anteriormente, o inconsciente seria o discurso de "outro em mim" que ao se relacionar com o imaginário, se torna capaz de propiciar uma visão distorcida da realidade, como esta visão de que a relação entre oprimido-opressor é a correta e deve permanecer. Quando Freire explicita que a luta se trava entre serem espectadores ou atores, tem-se a luta, nos termos de Castoriadis, entre seguir a lei do outro ou seguir a sua própria lei. E, para o autor, seguir a sua própria lei seria tornar-se um indivíduo autônomo.

Ao analisar as contribuições dos dois autores, percebem-se pontos importantes, como a visão de que a realidade apresenta problemas sérios decorrentes da relação oprimido-opressor, que somente podem ser superados pela práxis, por uma ação humana transformadora. Como objetivo e meio desta práxis, tem-se a autonomia, que acima de qualquer coisa deve ser uma autonomia coletiva. Além destes, tem-se a visão dinâmica da práxis, como uma ação em que os indivíduos constroem e modificam, mas também por ela são construídos e modificados. Com efeito, a leitura desses autores permite-nos argumentar que, quando se trata da temática do empoderamento, em que se versa sobre uma conquista de poder — um poder diferente do comumente pensado - , deve-se falar na verdade de práxis, ou seja, da conquista da autonomia, individual, mas principalmente coletiva, e no respeito à vocação do homem de ser mais. 
Partindo desta discussão, resgatamos uma definição de empoderamento que se entrelaça com a práxis, deslocando-se do foco na apropriação de recursos para a ênfase na autonomia: “(...) aumento de poder e autonomia pessoal e coletiva de indivíduos e grupos sociais nas relações interpessoais e institucionais, principalmente daqueles submetidos a relações de opressão, dominação e discriminação social" (Vasconcelos, 2003:23, grifos nossos). Essa definição revela de forma clara o fenômeno do empoderamento ao abordar a autonomia, seu caráter coletivo e a superação de uma condição opressora. Essa concepção de empoderamento coloca em questão o viés materialista trazido pela perspectiva neoliberal/neoconservadora, dando primazia aos recursos simbólicos, o que reforça a perspectiva emancipatória que estamos buscando consolidar. Partindo deste questionamento e depois de explicitadas as escolhas metodológicas, serão apresentadas as reflexões sobre o caso estudado.

\section{Opções metodológicas}

Este trabalho se orienta pela "epistemologia qualitativa” de González Rey (2005), que explicita que esse tipo de pesquisa se destina especialmente à análise de fenômenos que não podem ser aparentemente reconhecidos e explicados, pois contêm uma alta carga de elementos subjetivos e simbólicos, cujas significações não são claramente percebidas. Diante dessa realidade complexa, os sentidos subjetivos escapam às lentes de uma investigação de cunho positivista, em que se busca por meio de categorias universais a apreensão do fato estudado.

Nesse esteio, tendo em vista o caráter subjetivo do fenômeno abordado neste trabalho, buscaram-se formas adequadas de aproximação do empírico. O objetivo da pesquisa, como vimos anteriormente, é resgatar a centralidade dos recursos simbólicos para evidenciar que o empoderamento é possível mesmo em condições de pobreza, quando é considerado em uma perspectiva emancipatória. Assim, optou-se por analisar a atuação do "Programa Polos Reprodutores da Cidadania" da UFMG no Vale do Jequitinhonha de forma a compreender como o empoderamento pode ser evidenciado de acordo com o conceito que apresentamos e a partir dessa perspectiva.

É, portanto, um estudo de caso, o qual é considerado adequado quando se objetiva conhecer de forma profunda uma realidade específica. Segundo Roesch (1999), o estudo de caso possibilita um aprofundamento a respeito de um fenômeno de acordo com o contexto no qual ele se insere, podendo analisá-lo sob vários ângulos.

Para a compreensão do programa estudado e do funcionamento do projeto específico

— o "Vale de Cidadania" —, realizaram-se duas entrevistas com roteiros semiestruturados, uma com a subcoordenadora do programa e outra com um agente envolvido no projeto desde o seu início. Como expõe González Rey (2005), o que importa nesse tipo de pesquisa não é o número de entrevistas realizadas, mas a seleção de pessoas-chave, as quais, pela riqueza de seus depoimentos e informações acerca do fenômeno estudado, permitem ao pesquisador uma compreensão mais ampla do mesmo. 
Já para a apreensão dos sentidos subjetivos das mulheres acerca da participação no projeto em questão, optou-se pela realização de dinâmicas em grupo. Tais dinâmicas consistiram em exercícios de reflexão com as participantes do projeto, utilizando-se de recursos metafóricos. Essas dinâmicas de grupo são partes de um diagnóstico realizado pelo projeto, sob a orientação de uma antropóloga, que objetiva o entendimento mais profundo da realidade das mulheres e o embasamento de ações mais efetivas.

A dinâmica de grupo selecionada para a análise do fenômeno estudado denominou-se "Dinâmica Rio da Vida Coletivo", a qual objetivou justamente o entendimento das mudanças empreendidas na vida das mulheres pela participação no projeto. Essas mulheres foram então estimuladas a se colocarem em um rio que foi sendo desenhado em uma cartolina, de forma a localizarem os acontecimentos importantes, explicitando os desvios e as curvas vivenciadas na trajetória de cada uma delas e da associação. Elas foram instigadas a relatar sobre como era a vida delas antes, como se deu a inserção no projeto, dentre outros. Como suporte à dinâmica, foi utilizado um roteiro, o qual abarcou questões como: "Como vocês se relacionavam antes da formação do grupo e do 'Polos' começar a trabalhar com vocês?" e "O que significa cada símbolo do rio? (ex.: 'o que significa esta curva?')”.

Tanto as entrevistas quanto a dinâmica foram registradas com um gravador e, para o exame desses dados, optou-se pela análise de conteúdo. Segundo Rodrigues e Leopardi (1999), esta possibilita conhecer a subjetividade do outro e permite, devido à flexibilidade que lhe é inerente, apreender diferentes abordagens filosóficas do teor das falas. Os dados foram sistematizados por meio da criação de categorias resultantes da elaboração teórica feita anteriormente bem como de temas que surgiram ao longo das entrevistas, como sugere Bardin (2004), de modo que abordamos a questão do empoderamento na perspectiva neoliberal/ neoconservadora e na perspectiva emancipatória. O recurso ao itálico é utilizado para destacar alguns termos ou expressões-chave que se relacionam à argumentação empreendida, com o objetivo de orientar o leitor sobre qual parte exata se está falando. Além disso, os entrevistados são identificados como: subcoordenadora do programa, agente do projeto e participantes do grupo numeradas de 1 a 4. A partir da observância destes critérios metodológicos, a análise dos dados é apresentada a seguir.

\section{Objeto de estudo: o caso do "Programa Polos Reprodutores de Cidadania"}

\subsection{0 "Programa Polos" e o "Projeto Vale de Cidadania": uma visão geral}

O "Programa Polos Reprodutores de Cidadania" foi criado no ano de 1995 como um grupo de estudos e transformou-se em projeto de extensão. Este pertence à Faculdade de Direito da UFMG, mas conta com profissionais de diversas áreas de conhecimento. O programa é composto por vários projetos que visam atender a demandas distintas, embora estes sejam sempre interligados pela questão da luta pelos direitos humanos fundamentais. A metodologia do programa é pautada na constituição de capital social, no estabelecimento de redes sociais mis- 
tas e na mediação de conflitos. Essa metodologia se fundamenta em três núcleos temáticos, a saber: a cidadania, a subjetividade e a emancipação. Atualmente, o programa conta com uma equipe de cerca de 60 membros, entre professores, profissionais, alunos e funcionários, e possui projetos não só na região metropolitana de Belo Horizonte, mas também em outras localidades como o Vale do Jequitinhonha (Polos, 2012).

O Vale do Jequitinhonha é uma região marcada por alto grau de miserabilidade, sendo este, inclusive, um dos fatores que determinou a intervenção do programa. O primeiro projeto realizado pelo "Polos" no Vale do Jequitinhonha foi o denominado "18 de maio", que tinha como objetivo trabalhar na prevenção e no combate à exploração sexual de crianças e adolescentes. Os agentes do "Polos" fizeram inicialmente um diagnóstico na região em que identificaram esta questão como um problema grave e, diante disso, delinearam-se várias ações preventivas, de sensibilização e conscientização, além da estruturação de outras alternativas, como a geração de renda.

Inicialmente este trabalho abrangeu seis municípios, no entanto, para as ações de geração de renda, focou dois específicos, o de Padre Paraíso e o de Medina. Em Padre Paraíso, identificou-se um grupo já existente na comunidade, o "Clube de Mães Bordadeiras", o qual foi então o foco de trabalho do programa. A partir desse grupo os agentes propuseram a formação de uma cooperativa ou associação, pois se pressupunha que um grupo já existente possuiria uma identidade coletiva e vínculos entre as mulheres. Isso porque se sabe da importância da existência desses laços sociais e identitários para a formação de grupos como este, os quais contribuem para o sucesso e a sobrevivência do mesmo. No entanto, segundo o entrevistado, tais laços na realidade não existiam, uma vez que o grupo escolhido era muito mais um resultado do esforço de uma liderança comunitária do local do que uma iniciativa das mulheres participantes. E como será possível perceber, tal situação trouxe consequências determinantes para o grupo.

Devido a inúmeros fatores, o entrevistado argumentou que os agentes se depararam com uma realidade complexa e que exigiu um trabalho maior do que o planejado. $\mathrm{O}$ agente entrevistado relatou inúmeras dificuldades que, inclusive, surpreenderam os agentes envolvidos, como se pode observar no exemplo a seguir:

(...) a primeira vez que a gente foi fazer reunião lá e apresentar para elas o que a gente tava pensando em fazer com elas e tal, a gente montou uma apresentação, imprimimos um monte de transparências, fomos para lá e descobrimos que dois terços das mulheres que estavam na reunião não sabiam nem ler e escrever — eram analfabetas.

Outra dificuldade encontrada se deu a partir da constatação de que a maior parte das mulheres tinha problemas de visão e, por não terem acesso a atendimento médico, não conseguiam enxergar bem. Neste sentido, muito além do que os agentes do programa tinham se proposto a fazer, tornou-se necessário alterar a metodologia de intervenção utilizada e realizar um mutirão com um oftalmologista, a fim de fazer exames e confeccionar óculos para que assim as mulheres pudessem aprender a costurar. Uma primeira análise acerca da experiência 
do programa corrobora a argumentação sobre o caráter multifacetado da pobreza e da exclusão social, pois, muito além da carência financeira, essas mulheres possuem outros problemas diversos, desde questões de saúde até o analfabetismo.

Superadas essas etapas, iniciou-se o trabalho com o grupo. As primeiras ações visaram à formação desse grupo, envolvendo discussões sobre cooperativismo, economia solidária, desemprego, entre outros. Segundo o entrevistado, algumas dificuldades surgiram tanto pelo período curto de trabalho dos agentes em função das exigências de agenda (prazos para entrega de relatórios aos financiadores), quanto por questões do próprio grupo, como inquietude nas reuniões, a presença de um grande número de filhos durante as mesmas e também pela grande ansiedade por parte das mulheres em começar o trabalho de costura. Então se optou, em junho de 2006, por iniciar o trabalho de costura e, para isso, duas costureiras do próprio município foram contratadas e remuneradas pelo projeto para ensinarem a técnica às mulheres participantes. Após alguns meses, o programa contratou uma professora de Belo Horizonte para capacitá-las em patchwork, o que, segundo o entrevistado, foi um fator motivador para a manutenção do grupo que já começava a oscilar.

Mas, tempo depois, por questões de financiamento, o programa interrompeu o pagamento das professoras e propuseram a inclusão das mesmas no grupo. Inicialmente estas aceitaram a proposta, no entanto, com o passar do tempo outros problemas foram surgindo: “(...) problemas internos no grupo, de relações de poder que começaram a se estabelecer ali (...)". Diante disso, os agentes do programa buscaram modificar um pouco a atuação focando esses problemas de relacionamento interno do grupo.

Ao longo do tempo as visitas dos agentes ao Vale do Jequitinhonha foram ficando mais espaçadas, com a periodicidade de uma vez ao mês. Nessas visitas rápidas, de dois dias, os agentes faziam encontros com as mulheres tanto para discutir mais alguma temática importante, quanto para escutá-las a respeito de como estavam as coisas e o que tinha acontecido durante o mês que passou. E, em julho de 2007, durante o período de férias escolares, optouse pela realização de um trabalho diferenciado, "uma imersão na microrrealidade delas", em que quatro ou cinco membros da equipe ficaram hospedados no próprio espaço onde se realizam as atividades da associação. O entrevistado relata que essa foi uma iniciativa muito importante no sentido de perceber outros problemas internos do grupo, relacionados ao trabalho, de que até então eles não tinham conhecimento. Segundo ele, existiam problemas graves de relações de poder, o que não permitia o estabelecimento de um espaço de comunicação entre as mulheres.

E, como argumenta o entrevistado, as relações observadas dentro da associação nada mais são do que a reprodução de uma realidade social, em que essas mulheres sofrem constante opressão, seja dos companheiros, seja do restante da sociedade. E essa reprodução acaba por impossibilitar que o grupo seja um espaço democrático e de livre expressão. Ao retornar a Belo Horizonte, os agentes discutiram novas possibilidades para o projeto, o que culminou no entendimento de que era necessário buscar uma ajuda externa ao programa. Atualmente, uma consultora com formação em antropologia foi contratada e a primeira ação empreendida foi um diagnóstico que objetiva conhecer mais a realidade das mulheres e o trabalho que já foi 
feito, de forma a contribuir cada vez mais para que essas mulheres consigam sair da condição de exclusão.

\subsection{A atuação do "Programa Polos" no Vale do Jequitinhonha: uma análise do empoderamento}

O eixo central deste trabalho é a ampliação do conceito de empoderamento e as possibilidades para sua concretização por aqueles que vivem em condições de pobreza e exclusão social. Para fins de análise, a partir do que foi discutido na literatura, optou-se por desmembrar o conceito de empoderamento em duas perspectivas: a neoliberal/neoconservadora e a emancipatória. A primeira corresponde aos avanços alcançados em termos de melhoria das condições econômicas, ou seja, se houve ou não aumento de renda ou benefícios desta natureza. $\mathrm{E}$ a segunda, a emancipatória, é constituída de elementos de caráter mais subjetivo, como mudanças em relação à visão de mundo, à postura política, à autonomia. Partindo-se dessa sistematização, os resultados da pesquisa são apresentados na sequência.

\subsubsection{A perspectiva neoliberal/neoconservadora: as dificuldades da "Associação Bela Vista"}

A mesorregião do Jequitinhonha pode se dividida em três espaços diferentes, o Alto, o Médio e o Baixo Jequitinhonha. Como apontado por Silva (2012), a situação de precariedade na região decorre em certa medida de um enfraquecimento das atividades primárias que, aliado a um perfil educacional carente da população e ao baixo nível tecnológico, acaba por delinear uma realidade de pobreza e exclusão social. E assim como a realidade predominante no Vale do Jequitinhonha, as famílias residentes no bairro Bela Vista, no qual o Programa "Polos" atua, vivem em condições de pobreza, com renda familiar média de cerca de cem reais e, segundo a coordenadora do Programa "Polos", muitas são beneficiárias do Programa Bolsa Família. Bela Vista é o maior bairro da cidade e, também por isso, muito heterogêneo, abrangendo desde casas de "chão batido" e sem acesso a saneamento, até algumas de alvenaria com melhor infraestrutura.

Além dessas questões, existem outras que contribuem para a realidade de dificuldade dessas famílias, como o grande número de filhos e o alto grau de desemprego na cidade, o que resulta em consequências desastrosas, como a prostituição de crianças e adolescentes. Diante deste contexto, a dimensão econômica revela-se fundamental. No entanto, devido a fatores diversos, a associação até então não se concretizou como uma alternativa de geração de renda para as participantes. Como explicita uma das participantes:

(...) fiquei desanimada, porque eu achei que não chegava nada pra mim não, só um dinheirinho. Isso aí ninguém pode contar com o dinheiro de nada. Se chegar conta de água, conta de luz, a 
gente não pode falar "essa conta eu vou pagar com o dinheiro de lá, de onde eu tô trabalhando", não pode fazer isso, né, porque se for esperar, né, fica sem pagar (Participante 1).

A ausência de retornos econômicos expressivos incomodou aos agentes do programa que se questionam pelo fato de esses resultados não terem sido alcançados. Uma primeira análise feita por eles aponta algumas questões práticas, como falta de organização, pouca permanência no trabalho, o fato de ainda estarem aprendendo. O agente observa:

Elas sempre se queixaram muito de não ter o retorno econômico das atividades. E várias vezes elas tinham algumas demandas, encomendas, e elas simplesmente não davam conta, não faziam. Então a gente ficava assim perdido em relação a isso: elas vivem se queixando de que não geram renda, mas também não fazem as encomendas que têm; elas ao invés de trabalharem mais para poderem ganhar mais, produzir mais e vender mais, acabam se reunindo precariamente, 4 ou 5 vezes por semana mas em horários completamente malucos, curtos.

A ausência de iniciativa por parte das mulheres ao mesmo tempo que elas reivindicavam esses retornos financeiros parece algo contraditório. Por um lado, isso pode ser resultado de outras questões já discutidas, como as relações de poder e as próprias questões de gênero. Por outro lado, a coordenadora aventa a possibilidade de uma atuação paternalista por parte do programa, na medida em que a iniciativa foi do mesmo, pois foi este que conseguiu todas as matérias-primas, e algumas vezes ajudando a vender os produtos; então pode ter se estabelecido, mesmo que não intencionalmente, uma relação de dependência prejudicial ao grupo.

No entanto, argumenta-se que tal paradoxo pode ainda ser visto de outra perspectiva. Se observada a parte final do relato do agente, tem-se uma descrição do que seria, em essência, a lógica do capital: "trabalhar mais para poderem ganhar mais, produzir mais e vender mais". Destaca-se que, até então, estas mulheres estavam aquém dessa lógica e, portanto, propor esse tipo de organização seria inseri-las na mesma. Cabe então um questionamento: seria essa inserção desejada por elas? Esse aparente desinteresse em atender as encomendas, esse não fazer, não poderia se revelar, portanto, uma forma de resistência? Neste contexto, pode existir uma não identificação das mulheres com este tipo de organização do trabalho, de forma ordenada e repetitiva.

Esse contexto aponta para as outras funções da existência do grupo, que não a de provisão financeira. Uma dessas outras funções identificadas é a terapêutica, uma vez que elas se reúnem, se dedicam a atividades manuais, utilizam a criatividade, ou seja, se distanciam da realidade de opressão em que vivem. E, nesse sentido, elas recusarem a inserção em uma organização de trabalho que é opressora torna-se compreensível. Mas, de qualquer forma, o interesse em obter esses retornos financeiros aparece entre as mulheres, como se pode perceber na fala da participante 2: “(...) ainda não ta dando, né, mais vai crescer. Vai crescendo, crescendo de pouco em pouco a pouco, né, e a nossa esperança é o dinheiro crescer, enramar, pelo mundo todo". 
Desta forma, no que diz respeito à perspectiva neoliberal/neoconservadora, não foram identificados indícios de empoderamento, uma vez que a associação ainda não se consolidou como uma alternativa de renda para estas mulheres. De qualquer forma, estas outras funções, às quais pode ser atribuída a existência do grupo, refletem-se diretamente na avaliação de possíveis indícios de empoderamento em uma perspectiva emancipatória, como pode ser observado a seguir.

\subsubsection{A perspectiva emancipatória: as transformações subjetivas do grupo de mulheres do Jequitinhonha}

No que tange à perspectiva emancipatória, vários aspectos relevantes puderam ser observados, dentre os quais esta situação relatada pelo agente entrevistado:

(...) no ano passado, a secretária de assistência social lá do município, que é uma autoridade, que tem um certo poder, pediu para elas a chave de uma lojinha que elas têm lá para poder comercializar os produtos. Ela disse que ia pintar, eu acho, então ela pegou a chave, elas emprestaram e depois não devolveu. E isso incomodou elas, então elas fizeram uma reunião entre elas lá para discutir isso, disseram que não concordavam, que ela deveria ter devolvido a chave, ou que pelo menos ter dado alguma explicação. Elas fizeram uma ata daquela reunião e foram tentar discutir isso assim, levaram isso pra gente e para a própria secretária (...).

Este é um exemplo extremamente interessante que demonstra um posicionamento das mulheres diante de uma situação de descontentamento, em que elas se sentiram ofendidas pela figura de autoridade e, diante disso, se organizaram, discutiram e a partir daí estabeleceram um plano de ação para resolver o problema. Aqui se pode observar uma atuação como grupo e a adoção de certa postura política. Essa atitude, que poderia até ser considerada algo natural, manifestada por um grupo no qual suas integrantes inicialmente mal conseguiam se expressar, revela-se um salto qualitativo relevante.

Durante a dinâmica realizada e quando questionadas sobre como era a vida delas antes de entrarem no grupo, as mulheres selecionaram palavras como tristeza, depressão e, principalmente, solidão. Esse é um discurso bastante recorrente, demonstrando de certa forma que elas viviam sempre muito sozinhas e isoladas. Nesse aspecto, a criação da associação significou o estabelecimento de novos vínculos sociais, ainda que com problemas de relacionamento interno. Essa percepção em relação ao grupo passa então a ser expressa pela ideia da formação de uma família e por sentimentos como o amor. Essa mudança proporcionada pela constituição do grupo fica clara no relato de uma das mulheres:

Eu cheguei aqui e não conversava com ninguém, eu era calada, às vezes chorava, ia embora caladinha sem dar satisfação a ninguém. Aí eu fui e puxei conversa (...), as mulheres que estavam aqui me apoiaram, me deram bastante força! Foi uma família que eu encontrei aqui! E todas me 
ajudaram! E meu rio tá andando e vou atrás dele! (fazendo referência à "Dinâmica do Rio da Vida"). (Participante 3)

Outro aspecto interessante presente no discurso das mulheres é a satisfação pelo aprendizado obtido na associação. Frequentemente elas ressaltam que o objetivo delas ao entrar no grupo foi o de aprender coisas novas às quais elas não tinham acesso. Tal questão da aprendizagem reflete-se diretamente na autoestima dessas mulheres que, pela condição de opressão em que vivem, na maioria dos casos é muito baixa. A recuperação da autoestima é muito importante e reflete-se na posição adotada por essas mulheres diante da própria vida. Isso fez com que elas de certa forma passassem a confiar mais em si mesmas e, portanto, ultrapassassem barreiras como as dificuldades de se relacionar e o medo de se expressar e ser repreendido pelo outro.

Oh moça, minha vida mudou muito, porque antes assim, eu tenho o meu jeito meio assim, de medo. Mas até para comunicar com as pessoas, eu tinha tanta vergonha que eu não conseguia nem olhar para essas pessoas. É que eu me achava assim, que todo mundo que eu me aproximava dele me dava uma má resposta ou não queria me ouvir (...). Ainda tenho, mas já não é mais aquilo, já converso um pouco mais do que era antes. (Participante 4)

O relato demonstra em certa medida a realidade dessas mulheres da associação. A percepção da participante de que todo mundo — ou seja, ela não exclui ninguém — não gostaria de escutar o que ela tem a dizer ou então a trata mal é uma revelação sintomática de quão precárias são as suas relações pessoais. Do seu discurso depreende-se que não há espaço para a sua livre expressão e, o pior, que ela não percebe o interesse por parte do outro, talvez nem mesmo do seu companheiro, em relação àquilo que ela tem a dizer. Neste sentido, ao admitir que a partir daquele grupo ela obteve avanços nesse caminho, reconhece que há um espaço em que a sua opinião vai ser ouvida. Essa mudança de comportamento foi percebida pelo agente entrevistado, que relatou esse novo posicionamento das mulheres na reunião: "Elas passaram a falar sobre o que elas estavam sentindo, a se colocar".

Segundo ele, outras questões relevantes podem ser observadas. O agente relatou que algumas mulheres começaram a pensar sobre a sua vida familiar, ou seja, começaram a problematizar a relação com o marido. Tendo em vista a já discutida presença forte das questões de gênero (machismo) na comunidade, esse é um passo pequeno, mas extremamente significativo. Ao começar a pensar sobre essa questão, assim como sobre várias outras, elas iniciam o processo de desnaturalização da realidade que é dada, ou seja, este pode ser um caminho para que elas percebam que nem tudo que lhes foi dado como certo deve ser da forma como se apresenta.

Outro ponto ressaltado pelo agente é que a constituição do grupo teria proporcionado a essas mulheres a capacidade de vislumbrar perspectivas para o futuro, a capacidade de sonhar. Segundo ele "Era muito comum a gente chegar lá no começo e perguntar para elas, ah, o que você sonha?”. E várias respondiam: “Olha, eu não tenho sonho". Ao se envolverem na 
associação, elas passaram a pensar no futuro e nas chances de realmente começarem a obter retornos financeiros. Essas perspectivas constituem-se razões para continuarem trabalhando, enfim, motivação para a vida.

Outro fato interessante relatado pelo agente merece ser destacado como exemplo de mudança, desta vez em relação à consciência acerca do espaço que ocupam:

(...) a gente aqui do Bela Vista sempre foi muito discriminado, quando a gente sai aqui e vai andar em outros espaços da cidade, os outros acham que a gente é marginal, que a gente não presta e tal, e a gente quer mostrar para todo mundo agora que tem coisa boa aqui neste bairro sabe?

Esta experiência reflete uma mudança importante em relação à percepção acerca do espaço em que elas vivem e à maneira pela qual elas querem ser reconhecidas pelos outros. $\mathrm{O}$ argumento de que o desejo é o de levar ao conhecimento de todos as coisas boas do bairro de certa forma demonstra o orgulho pelo trabalho que está sendo feito. Diante disso, portanto, a entrevistada demonstra que o julgamento dos outros é equivocado. Há também na fala dela o sentimento de que elas pertencem a um grupo, o qual elas estão defendendo do preconceito por meio dos resultados do seu trabalho. Além desses aspectos, a questão identitária também deve ser destacada, pois o pertencimento a um grupo, reconhecido como legítimo e de referências positivas, também contribuiu para a construção da identidade das próprias mulheres. Elas explicitam que participar do grupo possibilitou a elas um conhecimento maior de si mesmas, de alguém que antes ficava em segundo plano na relação de submissão ao marido, aos filhos e à própria sociedade.

A partir da análise das questões apresentadas, pode-se perceber que várias mudanças significativas ocorreram, tendo em vista o contexto social, econômico e familiar destas mulheres. Assim, no que tange aos recursos simbólicos do conceito de empoderamento, vários indícios foram identificados: maior participação nas reuniões, restabelecimento da autoestima, estreitamento das relações sociais, problematização da própria vida, desnaturalização da realidade, e todos os demais pontos abordados. Fala-se de mudança real da visão de mundo e de alteração da realidade como ela é apresentada. Nesse sentido, está-se falando em indícios de um processo de empoderamento na perspectiva emancipatória, tal como ele foi definido neste estudo, pois o foco se desloca dos recursos materiais para os recursos simbólicos, evidenciando que é possível o empoderamento mesmo em condições de pobreza e que estas mulheres estão tentando superar sua situação de exclusão por meio de sua participação no grupo, pois nele podem problematizar e praticar questões relacionadas à autonomia e à práxis.

\section{Considerações finais}

O objetivo principal deste trabalho foi resgatar a centralidade dos recursos simbólicos para consolidar uma perspectiva emancipatória de empoderamento e evidenciar que o mesmo é possível mesmo em condições de pobreza. Buscou-se abordar o empoderamento na perspecti- 
va neoliberal/neoconservadora e na perspectiva emancipatória a partir das evidências empíricas do "Projeto Vale de Cidadania", do "Programa Polos de Cidadania". A análise desta perspectiva emancipatória apontou que o empoderamento pode ser considerado em sua forma mais ampla, envolvendo noções como autonomia, práxis e coletividade. É preciso superar os limites do conceito quando este se restringe apenas a ações de microemancipação, as quais se circunscrevem ao sujeito - e não se referem ao coletivo e nem configuram mudanças significativas da realidade.

Ao analisar o caso estudado, várias questões importantes emergem e propõem reflexões sobre a própria atuação dos projetos sociais bem como sobre as reais possibilidades da concretização do empoderamento. O caso corrobora o caráter multifacetado da pobreza e da exclusão social, o que ficou claro nas diversas dificuldades encontradas pelo programa que, por consequência, teve de se desdobrar em várias frentes de ação para dar conta de uma realidade complexa. $\mathrm{O}$ caso estudado aponta contribuições importantes no que tange à metodologia de intervenção utilizada, embora não tenha sido objetivo deste trabalho detalhá-la passo a passo. A análise do projeto em questão suscita questões intrigantes, dentre as quais: como as mulheres poderiam se organizar a fim de gerar renda? Como dar passos maiores em relação à dimensão simbólica? O debate empreendido aqui sobre o empoderamento objetivou em certa medida apontar caminhos, bem como trazer à tona uma realidade que por vezes é remediada, mas não têm eliminadas as suas causas mais profundas.

Faz-se necessário reconhecer esse processo de empoderamento como algo inacabado, não por uma limitação da atuação do programa, mas pela própria essência do fenômeno: a autonomia e a práxis. Diante da realidade em que as mulheres se encontram, os avanços foram expressivos, mas ainda assim devem ser considerados passos iniciais de um longo caminho a ser percorrido. A autonomia apresenta-se assim como um devir, direito de todas as pessoas e que cabe a elas buscá-lo. Argumenta-se que a atuação do programa foi fundamental para desencadear essas mudanças identificadas na "Associação Bela Vista", embora deva se reconhecer que foram conquistas de cada uma das mulheres e, principalmente, do grupo como um todo. Tendo em vista a importância do tema, novas pesquisas empíricas deveriam ser realizadas de forma a aprofundar a discussão de como o empoderamento pode ser concretizado.

\section{Referências}

ANTUNES, Marta. O caminho do empoderamento: articulando as noções de desenvolvimento, pobreza e empoderamento. In: ROMANO, Jorge O.; ANTUNES, Marta. Empoderamento e direitos no combate à pobreza. Rio de Janeiro: ActionAid Brasil, 2002. p. 91-116.

BARDIN, Laurence. Análise de conteúdo. 3. ed. Lisboa: Edições 70, 2004.

BRONZO, Carla B. Políticas locais de inclusão social, autonomia e empoderamento: reflexões exploratórias. In: ENCONTRO DA ASSOCIAÇÃO NACIONAL DE PÓS-GRADUAÇÃO EM ADMINISTRAÇÃO, 
30, 2006, Salvador. Anais... Salvador: Anpad, 2006. 1 CD ROM.

CASTORIADIS, Cornelius. A instituição imaginária da sociedade. Rio de Janeiro: Paz e Terra, 1982.

FREIRE, Paulo. Pedagogia do oprimido. 14. ed. Rio de Janeiro: Paz e Terra, 1985.

GOHN, Maria da G. Empoderamento e participação em políticas sociais. Saúde e Sociedade, v. 13, n. 2, p. 20-31, 2004.

GOMÀ, Ricard. Processos de exclusão e políticas de inclusão social: algumas reflexões conceituais. In: CARNEIRO, Carla B. L.; COSTA, Bruno L. D. (Org.). Gestão social: o que há de novo? Belo Horizonte: Fundação João Pinheiro, 2004. p. 13-24.

GONZÁLEZ REY, Fernando. Pesquisa qualitativa e subjetividade: os processos de construção da informação. São Paulo: Pioneira Thomson Learning, 2005.

GUSTIN, Miracy B. S. Resgate dos direitos humanos em situações adversas de países periféricos. Revista da Faculdade de Direito, n. 47, p. 181-216, 2005.

HOROCHOVSKI, Rodrigo R.; Empoderamento: definições e aplicações. In: ENCONTRO ANUAL DA ANPOCS, 30, 2006, Caxambu. Anais... Caxambu: Anpocs, 2006. p. 1-29.

HOROCHOVSKI, Rodrigo R.; MEIRELLES, Gisele. Problematizando o conceito de empoderamento. In: SEMINÁRIO NACIONAL DE MOVIMENTOS SOCIAIS, PARTICIPAÇÃO E DEMOCRACIA, 2, 2007, Florianópolis. Anais... Florianópolis: UFSC, 2007. p. 485-506.

MARTINS, Poliana C. et al. Democracia e empoderamento no contexto da promoção da saúde: possibilidades e desafios apresentados no Programa Saúde da Família. Physis, v. 19, n. 3, p. 679694, 2009.

PASE, Hemerson L. Capital social e empoderamento. In: SEMINÁRIO NACIONAL MOVIMENTOS SOCIAIS, PARTICIPAÇÃO E DEMOCRACIA, 2, 2007, Florianópolis. Anais... Florianópolis: UFSC, 2007. p. 250-265.

PERKINS, Douglas D. Speaking truth to power: empowerment ideology as intervention and policy. American Journal of Community Psicology, v. 23, n. 5, p. 765-794, 1995.

POLOS REPRODUTORES DE CIDADANIA. Disponível em: <www.polos.ufmg.br/index. php?option $=$ com_content\&view $=$ article\&id=181\&Itemid=238> . Acesso em: 10 mar. 2012.

RAPPORT, Julian. Empowerment meets narrative: listening to stories and creating settings. American Journal of Community Psychology, v. 23, n. 5, p. 795-807, 2005.

RODRIGUES, Maria S. P.; LEOPARDI, Maria T. O método de análise de conteúdo: uma versão para enfermeiros. Fortaleza: Fundação Cearense de Pesquisa e Cultura, 1999.

ROESCH, Sylvia M. A. Projetos de estágio e de pesquisa em administração: guia para estágios, trabalhos de conclusão, dissertações e estudos de casos. 2. ed. São Paulo: Atlas, 1999.

ROMANO, Jorge O. Empoderamento: recuperando a questão do poder no combate à pobreza. In: 
ROMANO, Jorge O.; ANTUNES, Marta (Org.). Empoderamento e direitos no combate à pobreza. Rio de Janeiro: Actionaid Brasil, 2002. p. 1-7.

SANT'ANA, Sarah M. A perspectiva brasileira sobre a pobreza: um estudo de caso do Programa Bolsa Família. Revista do Serviço Público, v. 1, n. 58, p. 5-35, jan./mar. 2007.

SEN, Amartya. Desigualdade examinada. Rio de Janeiro: Record, 2001.

SILVA, Delfina S. O. Médio Jequitinhonha, MG - populações ribeirinhas: um estudo de caso. Disponível em: <www.cenedcursos.com.br/medio-jequitinhonha-mg-populacoes-ribeirinhas-umestudo-de-caso.html>. Acesso em: 10 mar. 2012.

VALOURA, Leila de C. Paulo Freire, o educador brasileiro autor do termo empoderamento, em seu sentido transformador. Disponível em: < http://siteantigo.paulofreire.org/Crpf/CrpfAcervo000120>. Acesso em: 10 mar. 2012.

VASCONCELOS, Eduardo M. O poder que brota da dor e da opressão: empowerment, sua história, teorias e estratégias. São Paulo: Paulus, 2003.

Raquel de Oliveira Barreto é mestre em administração pelo Centro de Pós-Graduação e Pesquisa em Administração da Universidade Federal de Minas Gerais (Cepead/UFMG) e professora do Centro Universitário de Belo Horizonte (UNIBH).E-mail: admraquelf@hotmail.com.

Ana Paula Paes de Paula é doutora em ciências sociais pelo Instituto de Filosofia e Ciências Humanas da Universidade Estadual de Campinas (Unicamp), mestre em administração pública e governo pela Escola de Administração de Empresas de São Paulo da Fundação Getulio Vargas (FGV/EAESP) e professora titular da Faculdade de Ciências Econômicas da Universidade Federal de Minas Gerais (UFMG). E-mail: appaula@face.ufmg.br. 